\title{
A Case of Spontaneous Rupture of a Simple Hepatic Cyst
}

\author{
Junji Ueda, Hiroshi Yoshida, Nobuhiko Taniai, \\ Sho Mineta, Youichi Kawano and Eiji Uchida
}

Surgery for Organ Function and Biological Regulation, Graduate School of Medicine, Nippon Medical School

\begin{abstract}
We describe the spontaneous rupture of a simple hepatic cyst associated with a benign course. A 64-year-old woman was admitted for right upper quadrant pain. The patient denied a history of abdominal trauma. Abdominal computed tomography (CT) showed a huge solitary hepatic cyst (diameter, $10 \mathrm{~cm}$ ) in the right lobe. Part of the cyst surface was irregular, and the interior was heterogeneous on ultrasonography. Fluid retention was detected under the liver capsule. Spontaneous rupture of a nonparasitic hepatic cyst was suspected. The patient was admitted to our hospital for further evaluation and treatment. Examination of the abdomen revealed right upper quadrant pain but no signs or symptoms of peritonitis. One week after admission, CT revealed that the volume of fluid retained under the liver capsule had decreased. Percutaneous puncture was performed with a needle and an 8-French pigtail catheter under ultrasonographic guidance. Serous, brown fluid was aspirated. After percutaneous aspiration, the patient's symptoms resolved. Minocycline hydrochloride was given daily by intravenous injection for 7 days. The catheter was then removed. There has been no evidence of recurrence after 1 year.
\end{abstract}

(J Nippon Med Sch 2010; 77: 181-185)

Key words: hepatic cyst, rupture, nonparasitic cyst

\section{Introduction}

Nonparasitic cystic disease of the liver occurs in $5 \%$ to $10 \%$ of the population. The incidence sharply rises with age. The pathogenesis is related to the type of cyst. Simple cysts may be solitary or multiple and are lined by cuboidal epithelium. Such cysts are attributed to the abnormal in utero development of intrahepatic bile ducts ${ }^{1}$. Cyst rupture into the peritoneal or pleural cavities may be caused by trauma, although spontaneous rupture has also been reported ${ }^{2-8}$. Rupture of a nonparasitic cyst is an unusual event that requires emergency surgery ${ }^{4}$. We describe the spontaneous rupture of a simple hepatic cyst with a benign course.

\section{Case Report}

A 64-year-old woman was admitted for right upper quadrant pain. The patient denied a history of abdominal trauma. There was no family history of renal failure or cystic disease of the liver or kidneys. A computed tomographic (CT) scan of the abdomen showed a large solitary hepatic cyst (diameter, 10 $\mathrm{cm})$ in the right lobe. Part of the cyst surface was

Correspondence to Hiroshi Yoshida, MD, Department of Surgery, Nippon Medical School, 1-1-5 Sendagi, Bunkyo-ku,

Tokyo 113-8603, Japan

E-mail: junji0821@nms.ac.jp

Journal Website (http://www.nms.ac.jp/jnms/) 


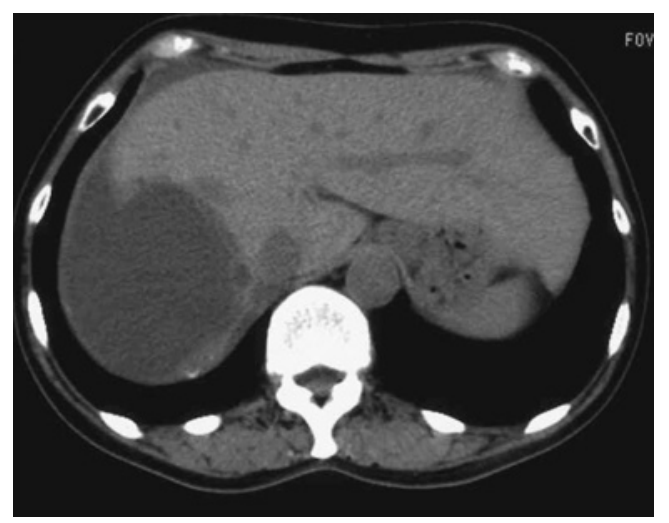

Fig. 1 An abdominal computed tomographic scan, showing a huge solitary hepatic cyst (diameter, $10 \mathrm{~cm}$ ) in the right lobe. The cyst surface was irregular, and interior was heterogeneous on ultrasonography. Fluid retention was detected under the liver capsule.

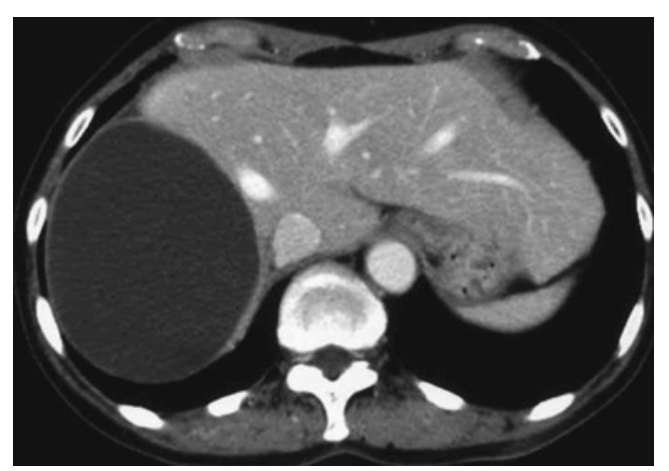

Fig. 2 One week after admission, computed tomography revealed that the volume of fluid retained under the liver capsule had decreased.

irregular, and the interior was heterogeneous on ultrasonography. Fluid retention was detected under the liver capsule (Fig. 1). Spontaneous rupture of a nonparasitic hepatic cyst was suspected. The patient was admitted to our hospital for further evaluation and treatment. Physical examination on admission showed no jaundice, spider angioma, or palmar erythema. There were no abnormalities of the chest or heart. Examination of the abdomen revealed right upper quadrant pain but no signs or symptoms of peritonitis. One week after admission, CT revealed that the volume of fluid retained under the liver capsule had decreased (Fig. 2). Percutaneous puncture was performed with the use of a needle and an 8-French pigtail catheter (Ultrasonic Guided

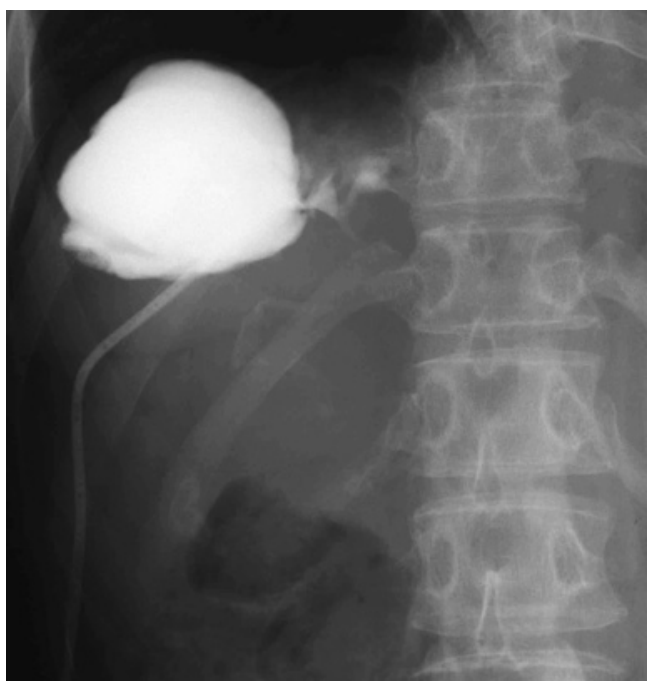

Fig. 3 After the removal of approximately $50 \mathrm{~mL}$ of fluid, contrast medium was injected to check for communications between the cyst and the biliary tree and to confirm the absence of leakage into the peritoneal cavity.

One-step Drainage Set type S, Hakko Shoji, Co., Ltd., Tokyo, Japan) under ultrasonographic guidance. Serous, brown fluid was aspirated. After the removal of approximately $50 \mathrm{~mL}$ of fluid, contrast medium was injected to check for communications between the cyst and the biliary tree and to document the absence of leakage into the peritoneal cavity (Fig. 3). After complete aspiration of the cyst fluid, $200 \mathrm{mg}$ of minocycline hydrochloride dissolved in $10 \mathrm{~mL}$ of saline was injected into the cyst, and the catheter was flushed with $10 \mathrm{~mL}$ of saline (total volume of saline, $20 \mathrm{~mL}$ ). The catheter was then clamped for 30 minutes, as we have recommended previously ${ }^{9}$. After percutaneous aspiration, the patient's symptoms resolved. Minocycline hydrochloride was injected daily for 7 days, and the catheter was removed. There has been no evidence of recurrence after 1 year.

\section{Discussion}

Simple nonparasitic hepatic cysts are thought to be congenital. During embryogenesis, aberrant or excessive numbers of intrahepatic bile ducts develop and consequently dilate to form hepatic cysts. Adult polycystic liver disease is a genetic disease that is usually associated with polycystic kidney disease, in 
which the entire liver is occupied by cysts $^{10}$. Simple hepatic cysts are common benign lesions that are usually asymptomatic and require no treatment. Cyst rupture into the peritoneal or pleural cavity may be caused by trauma, although spontaneous rupture occasionally occurs ${ }^{2-8}$. Other complications, such as obstructive jaundice ${ }^{11}$, intracystic hemorrhage ${ }^{6.12-16}$, and infection ${ }^{17-24}$, develop in $5 \%$ of patients. The two most common complications of nonparasitic hepatic cysts are intracystic hemorrhage and infection, often leading to pain. Symptoms are usually caused by space occupation by the cysts and pressure exerted by adjacent structures. The severity of symptoms depends on the size, number, and location of cysts. Patients frequently complain of chronic abdominal pain (right upper quadrant or epigastric), abdominal fullness, early satiety, dyspnea, increased abdominal girth, or vomiting. Spontaneous rupture of hepatocellular carcinoma has occurred occasionally ${ }^{2526}$, but spontaneous rupture appears to be a rare complication of nonparasitic hepatic cysts $^{27-36}$. Cyst rupture causes diffuse abdominal pain, as well as clinically significant intra-abdominal hemorrhage in some patients.

In the management algorithm for patients with cystic disease, clinicians must be certain of the diagnosis and carefully determine if and when surgery is indicated. Symptoms are usually nonspecific, and the diagnosis is one of exclusion, i.e., ruling out other possible conditions. ${ }^{1}$. Treatment is indicated if cysts are symptomatic, if complications occur, or if neoplastic growth is suspected ${ }^{337.38}$. Because our patient had no signs or symptoms of peritonitis, clinical observation and conservative treatment were the procedures of choice. Because the hepatic cyst had ruptured into the liver capsule, the fluid did not enter the peritoneal cavity.

The technique of open cyst deroofing or fenestration was first described by Lin et al in $1968^{39}$. This procedure has been recommended by several groups and been used successfully to treat simple hepatic cysts. It is particularly useful in patients with only one or several large cysts in whom the mass effect of such cysts can be significantly reduced $^{40}$. More radical approaches, such as hepatic resection, have been advocated for the treatment of extremely large cysts. Hepatic resection has been shown to be a safe and effective procedure that provides complete and permanent symptomatic relief in the absence of diffuse polycystic disease of the liver ${ }^{40}$. Current surgical management relies on fenestration or deroofing of the cyst, with or without placement of an omental flap into the residual cavity to prevent the edges from co-apting. Recently, a laparoscopic approach to this technique has been shown to be practical and safe. Compared with laparotomy, minimally invasive surgery is associated with less postoperative pain and disability, a shorter hospital stay, and superior cosmetic results ${ }^{41}$.

Recent trends in the management of symptomatic hepatic cysts have shifted to minimally invasive procedures, such as percutaneous treatment and laparoscopic deroofing of the cyst wall ${ }^{42}$. Previous studies have used alcohol as a sclerosing agent, but the usage conditions have varied considerably, such as the exposure time to ethanol, the concentration and volume of ethanol, and the number of sclerotherapy sessions ${ }^{9.4243}$. Percutaneous cyst aspiration or drainage without sclerotherapy is considered ineffective and carries a high risk of recurrence because secretions from the epithelial cell lining of hepatic cysts inhibit cyst obliteration. The use of sclerosing agents has been recommended to promote coagulation-induced necrosis of the cyst epithelium and to definitively obliterate cysts ${ }^{44}$. Various sclerosing agents have been injected into hepatic cysts. Ethanol has been used, but can cause pain, fever, and intoxication. More recently, minocycline hydrochloride has been successfully used to treat hepatic cysts ${ }^{9,4}$. The strong acidity of minocycline hydrochloride has been suggested to kill the secretory cells of hepatic cysts, which are then resorbed and shrink ${ }^{9,43}$.

There is no standard strategy for the management of hepatic cyst rupture. Emergency laparotomy should be performed in patients with signs and symptoms of acute abdomen or abdominal bleeding. In some patients with no evidence of peritonitis, clinical observation and conservative treatment may be the option of choice ${ }^{4}$. 


\section{References}

1. Gall TM, Oniscu GC, Madhavan K, Parks RW, Garden OJ: Surgical management and longterm follow-up of non-parasitic hepatic cysts. HPB (Oxford) 2009; 11: 235-241.

2. Klingler PJ, Bodner E, Schwelberger HG: Late complication after laparoscopic fenestration of a liver cyst. Surg Laparosc Endosc 1998; 8: 76-77.

3. Karavias DD, Tsamandas AC, Payatakes AH, et al.: Simple (non-parasitic) liver cysts: clinical presentation and outcome. Hepatogastroenterology 2000; 47: 1439-1443

4. Akriviadis EA, Steindel H, Ralls P, Redeker AG: Spontaneous rupture of nonparasitic cyst of the liver. Gastroenterology 1989; 97: 213-215.

5. Poggi G, Gatti C, Delmonte A, Teragni C, Bernardo G: Spontaneous rupture of non-parasitic hepatic cyst. Int J Clin Pract 2006; 60: 99-103.

6. Yamaguchi M, Kuzume M, Matsumoto $\mathrm{T}$, Matsumiya A, Nakano H, Kumada K: Spontaneous rupture of a nonparasitic liver cyst complicated by intracystic hemorrhage. J Gastroenterol 1999; 34: 645-648.

7. Andersson R, Tranberg KG, Bengmark S: Hemoperitoneum after spontaneous rupture of liver tumor: results of surgical treatment. HPB Surg 1988; 1: 81-83.

8. Lotz GW, Stahlschmidt M: Intra-abdominal bleeding after rupture of hepatic cyst. South Med J 1989; 82: 667.

9. Yoshida H, Onda M, Tajiri T, et al.: Long-term results of multiple minocycline hydrochloride injections for the treatment of symptomatic solitary hepatic cyst. J Gastroenterol Hepatol 2003; 18: 595598

10. Payatakes AH, Kakkos SK, Solomou EG, Tepetes KN, Karavias DD: Surgical treatment of non-parasitic hepatic cysts: report of 12 cases. Eur J Surg 1999; 165: 1154-1158.

11. Schwed DA, Edoga JK, Stein LB: Biliary obstruction due to spontaneous hemorrhage into benign hepatic cyst. J Clin Gastroenterol 1993; 16: 84-86.

12. Zanen AL, van Tilburg AJ: Bleeding into a liver cyst can be treated conservatively. Eur J Gastroenterol Hepatol 1995; 7: 91-93.

13. Chang SS, Chan CC, Wang SS, Chang FY, Lee SD Repeated episodes of spontaneous intracystic hemorrhage of hepatic cysts mimicking malignancy. Zhonghua Yi Xue Za Zhi (Taipei) 2000; 63: 256-261.

14. Hanazaki K, Wakabayashi M, Mori H, et al.: Hemorrhage into a simple liver cyst: diagnostic implications of a recent case. J Gastroenterol 1997; 32: 848-851.

15. Yoshida H, Onda M, Tajiri T, et al.: Intracystic hemorrhage of a simple hepatic cyst Hepatogastroenterology 2002; 49: 1095-1097.

16. Takahashi G, Yoshida H, Mamada Y, Taniai N, Bando K, Tajiri T: Intracystic hemorrhage of a large simple hepatic cyst. J Nippon Med Sch 2008; 75: 302305.

17. Yoshida H, Onda M, Tajiri T, et al.: Infected hepatic cyst. Hepatogastroenterology 2003; 50: 507-509.
18. Yoshida H, Tajiri $\mathrm{T}$, Mamada $\mathrm{Y}$, et al:: Infected solitary hepatic cyst. J Nippon Med Sch 2003; 70: 515-518.

19. Quigley M, Joglekar VM, Keating J, Jagath S: Fatal Clostridium perfringens infection of a liver cyst. J Infect 2003; 47: 248-250.

20. Egbuna O, Johnson S, Pavlakis M: Rupture of an infected liver cyst into the pericardium in a kidney transplant recipient with polycystic kidney disease. Am J Kidney Dis 2007; 49: 851-853.

21. Keven K, Bengisun JS, Altuntas F, et al.: Cystic infection of the liver in a maintenance haemodialysis patient. Nephrol Dial Transplant 2001; 16: 859-860.

22. Eloubeidi MA, Rockey DC: Infected hepatic cyst masquerading as abdominal aortic aneurysm. Dig Dis Sci 2000; 45: 1977-1980.

23. Bourgeois N, Kinnaert $P$, Vereerstraeten $P$, Schoutens A, Toussaint C: Infection of hepatic cysts following kidney transplantation in polycystic disease. World J Surg 1983; 7: 629-631.

24. Shoji F, Kitamura M, Shirabe K, Kai H, Akiyoshi T, Sugimachi K: Infected hepatic cyst in a patient with multiple hepatic cysts: report of a case diagnosed by change of ultrasonographic findings. Eur J Gastroenterol Hepatol 2000; 12: 703-705.

25. Yoshida H, Onda M, Tajiri T, et al.: Treatment of spontaneous ruptured hepatocellular carcinoma. Hepatogastroenterology 1999; 46: 2451-2453.

26. Yoshida H, Mamada Y, Taniai N, et al:: Long-term results of elective hepatectomy for the treatment of ruptured hepatocellular carcinoma. J Hepatobiliary Pancreat Surg 2008; 15: 178-182.

27. Tani A, Yoshida H, Mamada Y, Taniai N, Naito Z, Tajiri T: Case of biliary cystadenocarcinoma with intracystic bleeding. J Nippon Med Sch 2008; 75: 293297.

28. Shutsha E, Brenard R: Hepatic cyst rupture after coughing fit. J Hepatol 2003; 38: 870.

29. Arai H, Nagamine T, Suzuki H, et al.: Simple liver cyst with spontaneous regression. J Gastroenterol 2002; 37: 755-757.

30. Brunes L: Rupture of a solitary nonparasitic cyst of the liver. Report of a case. Acta Chir Scand 1974; 140: $159-160$

31. Ebre B, Schafhalter-Zoppoth I, Schumachter M, Krejs GJ: Giant cyst of the liver with complete resolution following blunt trauma to the abdomen. J Gastroenterol 1995; 33: 709-710.

32. Ayyash K, Haddad J: Spontaneous rupture of a solitary non-parasitic cyst of the liver. Case report. Acta Chir Scand 1988; 154: 241-243.

33. Ishikawa $\mathrm{H}$, Uchida $\mathrm{S}$, Yokokura $\mathrm{Y}$, et al: Nonparasitic solitary huge liver cysts causing intracystic hemorrhage or obstructive jaundice. J Hepatobiliary Pancreat Surg 2002; 9: 764-768.

34. Russell RC: Ruptured solitary cyst of the liver. Br J Surg 1972; 59: 919-920.

35. Morgenstern L: Rupture of solitary nonparasitic cysts of the liver. Ann Surg 1959; 150: 167-171.

36. Johnston JP: Solitary nonparasitic cyst of the liver with rupture. Harper Hosp Bull 1960; 18: 318-320.

37. Farinelli F, Chesi G, Mari R, Donega L: Partial rupture of biliary cyst of large dimensions. Clinical description and ultrasonic diagnosis. Minerva Med 
1988; 79: 903-906.

38. Yoshida H, Tajiri T, Mamada Y, et al:: Rapidly enlarging hepatobiliary cystadenoma. J Med Ultrasonics 2003; 30: 257-262.

39. Lin TY, Chen CC, Wang SM: Treatment of nonparasitic cystic disease of the liver: a new approach to therapy with polycystic liver. Ann Surg 1968; 168: 921-927.

40. Pitale A, Bohra AK, Diamond T: Management of symptomatic liver cysts. Ulster Med J 2002; 71: 106110.

41. Civello IM, Matera D, Maria G, Nigro C, Brandara F, Brisinda G: Laparoscopic fenestration of symptomatic non-parasitic cysts of the liver. Hepatogastroenterology 2005; 52: 849-851.

42. Zerem E, Imamovic G, Omerovic S: Percutaneous treatment of symptomatic non-parasitic benign liver cysts: single-session alcohol sclerotherapy versus prolonged catheter drainage with negative pressure. Eur Radiol 2008; 18: 400-406.

43. Yoshida H, Egami K, Onda M, Tajiri T, Uchida E: Treatment of symptomatic hepatic cyst by injection of minocycline hydrochloride. J Hepatobiliary Pancreat Surg 1996; 3: 491-494.

44. Blonski WC, Campbell MS, Faust T, Metz DC: Successful aspiration and ethanol sclerosis of a large, symptomatic, simple liver cyst: case presentation and review of the literature. World J Gastroenterol 2006; 12: 2949-2954.

(Received, December 8, 2009)

(Accepted, March 1, 2010) 